\title{
Considerations on a Lifecycle Model for Cyber-Physical System Platforms
}

\author{
Klaus-Dieter Thoben ${ }^{1}$, Jens Pöppelbu $\beta^{2}$, Stefan Wellsandt ${ }^{1}$, \\ Michael Teucke ${ }^{1}$, and Dirk Werthmann ${ }^{1}$ \\ ${ }^{1}$ BIBA - Bremer Institut für Produktion und Logistik, Hochschulring 20, \\ 28359 Bremen, Germany \\ and \\ University of Bremen, Germany \\ \{tho, wel, tck, wdi\} @biba. uni-bremen. de \\ ${ }^{2}$ Industrial Services Group, University of Bremen, \\ Wilhelm-Herbst-Str. 5, 28359 Bremen, Germany \\ jepo@is.uni-bremen.de
}

\begin{abstract}
Cyber-physical system platforms are information infrastructures connecting different cyber-physical systems and other information systems. This infrastructure is the base for realizing the "Industrie 4.0" paradigm aiming for collaborative industrial processes involving smart objects and smart factories. In inter-organizational value networks, a cyber-physical system platform becomes a shared resource that has to be managed cooperatively along its lifecycle. This paper looks at cyber-physical system platforms from a lifecycle perspective. It describes the complexity of networks of cyber-physical systems and cyber-physical system platforms within value networks and the resulting restrictions influencing their various lifecycles. A selection of different lifecycle models from literature is reviewed to extract aspects that provide a promising basis for the development of a specific lifecycle model of cyber-physical system platforms.
\end{abstract}

Keywords: Shared Resources, Industrie 4.0, Lifecycle Management, Shared Information Systems, Cyber-physical System Platform.

\section{Introduction and Problem Statement}

The concept of "Industrie 4.0" has been developed as a strategic agenda for the future development of the German manufacturing industry in the Internet-driven age. Industrie 4.0 assumes that industrial processes, services and applications will be based on so called cyber-physical systems (CPS). These CPS are embedded systems integrated into physical/mechanical systems. Sensors and actuators as well as hardware and software are part of them. For interaction with human beings, CPS can be endowed with human-machine interfaces. By using an integrated communication infrastructure, they can also interact with other systems [1]. Instances of such CPS may comprise smart machines, storage systems and production facilities that autonomously 
exchange information, trigger actions and control each other independently. A characteristic property of CPS is their vertical integration into business processes and networked manufacturing systems within factories and enterprises and their horizontal connections to CPS in other value networks to manage them in real time [2]. As such, CPS platforms can be considered a specific kind of shared resources [4] that are cooperatively managed by two or more independent companies to improve interorganizational processes within a value network. CPS platforms have been defined to act as federated, inter-organizational information systems [3] exchanging information between different CPS. The ongoing evolution of such technologies will increasingly allow implementing the already proclaimed Internet of Things.

Some research projects have already implemented parts of CPS platforms as prototypes. For example, Fraunhofer's Virtual Fort Knox project uses a CPS platform offering IT-based services and applications for the machine tool industry, based on a Software as a Service (SaaS) concept [5]. Another relevant research project in context of CPS platforms, called RFID-based Automotive Network (RAN), has developed and implemented concepts based on Electronic Product Code Information Services (EPCIS) specifications [6] for improving automotive value networks [7]. Some further related work is performed in a European context. This includes e.g. the research project FITMAN [8] within the Future Internet initiative [9], the EFFRA research association [9] within the Factories of the PPP Future initiative [10] and the recently established Industrial Internet Consortium (IIC) [11].

In addition to technical issues, the use of CPS in value networks also raises many economic, legal, and ethical issues, including, e.g., costs of introduction and operation, legal guarantee of proper operation of these systems, or their impacts on the workforce. Value networks are evolving continuously over their entire life-span, as new partners become part of the particular value chain, while former member companies leave. Main reasons for the mentioned continuous modification of value networks are dynamic influences of markets, products, technologies and processes [12]. Due to the dynamic nature of value networks, related CPS platforms are subject to ongoing change.

Frequent changes and complexity of the platforms challenge their management significantly. One driver of this challenge is the fact that hardware, software, services, applications and the network itself evolve along individual yet connected lifecycles. To our knowledge, the underlying lifecycle models for information exchange infrastructures in value networks (i.e.,CPS platforms) have not been investigated yet.

This paper aims to point out the importance of lifecycle models for the management of CPS within the Industrie 4.0 paradigm, particularly in relation to value networks. Its main argument is that lifecycle models are a viable approach to deal with this challenging complexity of CPS operating in dynamic enterprise networks. The main argument is derived from a review of different lifecycle models.

The paper's content is organized as follows. Section 2 describes the relation between CPS and value networks and points out requirements for efficient management of all elements of CPS platforms over the entire life span of such platforms. In section 3 , existing lifecycle models are examined. We derive suitable components from them, which can be used to create a holistic lifecycle concept for CPS platforms as shared resources in industrial value networks. Finally, some directions for future research are outlined in order to guide the development of a lifecycle model for CPS platforms. 


\section{Lifecycle Perspective on CPS Platforms}

Different elements are needed to realize the Industrie 4.0 paradigm in industrial value networks. Each value network typically consists of a number of companies as supply chain partners. To improve the processes within the value network, many CPS will be needed, operating at the involved companies to generate necessary information or trigger actions. In order to coordinate processes within the whole value network, one or more CPS platforms will connect different CPS with each other or with additional software systems as well as human beings through user interfaces. Moreover, CPS platforms can act as platforms for running services. This means CPS platforms and CPS are connected by information and communication technology for interacting with each other, as illustrated in Fig. 1. Furthermore, most companies are participating in more than one value network. This means that their CPS platforms and CPS have to connect to CPS platforms and CPS being part of other value networks. This increases the complexity of CPS platforms and CPS as well.

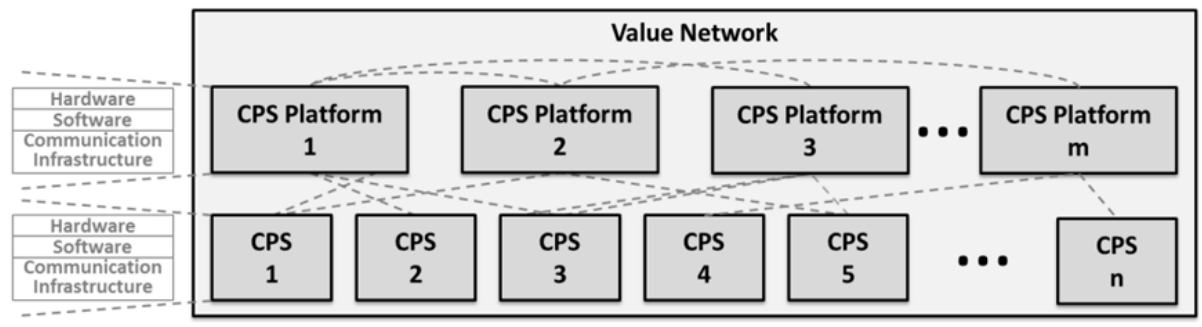

CPS: Cyber-physical systems

Fig. 1. Value network in context of Industrie 4.0 [2]

Obviously a high variety of different CPS platforms and CPS will be necessary to address all individual needs present in various value networks. In consequence, CPS platforms and CPS consist of a high variety of hardware, software, communication infrastructure and other components. To cope with the resulting complexity, interorganizational CPS platforms, which are used for connecting different CPS and other CPS platforms, need to be based on a common reference architecture.

Regarding the fact that CPS platforms are shared resources, the management of those CPS platforms has to consider the interests of all the involved partners. That means the whole functionality of the CPS platform, based on the hardware, software and communication technology, need to consider these interests.

These interests have to be taken into account during the whole lifecycle of the different hardware, software, communication infrastructure and other components. Moreover the lifecycle of the dynamically changing value network itself has to be considered. From a more generalized perspective the different lifecycles have to be synchronized to achieve high performance processes within the whole value network under respect of the interests of the involved partners. 
In the following specific characteristics of CPS platforms from a lifecycle perspective were investigated. The "lifecycle" concept can be found in different domains, such as manufacturing, information systems, service engineering or marketing. A key proposition of the concept is that a certain object (e.g., product, software and service) and its related states are described through a sequence of activities or situations. The beginning of the sequence is characterized by the creation of the object or its integration into a network of objects, while the end typically concerns its destruction. In between these two extremes, the lifecycle typically covers a dedicated activity representing an object's operational time.

Adopting a lifecycle perspective on shared CPS platforms, it is obvious that the lifecycles of the platforms may differ from that of the value network. Furthermore, the different components making up a CPS platform may have lifecycles that again differ from each other - the lifecycles of hardware components, for instance, may differ from those of system software components, and of services. In addition, different instances of components can have individual lifecycles that are running asynchronously. This implies that a large number of different, but interrelated lifecycles requires an efficient management to be sustainable.

Some interrelations between the lifecycles of the different entities and components are illustrated in a simplified way in Fig. 2.

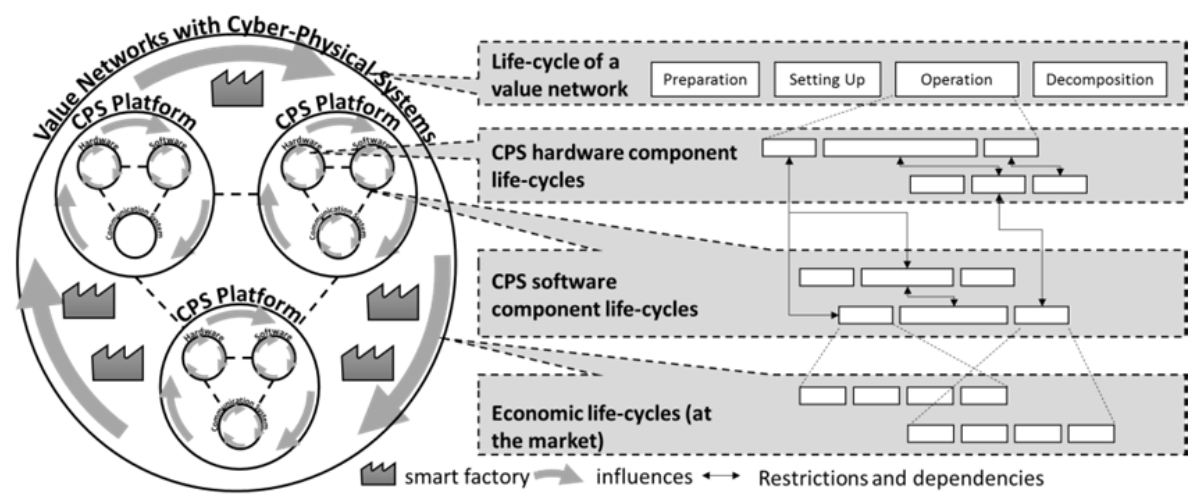

Fig. 2. Relations between lifecycles of different CPS platform components

We therefore see the following requirements to be fulfilled by a lifecycle model for CPS platforms in value networks:

- The value network lifecycle should adequately describe the development of the value network structure over time. Existing partners within a network might terminate existing relations between them and create new relations instead. In addition, new partners might be included into the value network, while previous partners leave the network, resulting in an overall expansion or contraction of the value network. A lifecycle model has to take into account the changing network structure. 
- Development of the hardware and software components and their dynamic relation should be adequately covered as well. New hardware components may be needed within the life of a CPS platform, thus existing hardware will be replaced by new or updated hardware components.

- Software may be updated, because improved or new software becomes available or because new hardware components may need new or reconfigured software.

- The technical lifecycles of components (e.g., hardware) are not independent of their respective economic lifecycles (i.e., the market situation). Thus, in addition to the technical perspective, a market perspective on the lifecycles of CPS platforms is required.

- Since value networks can employ thousands of individual CPS that must be produced (e.g., rare resources), operated (e.g., energy), maintained (e.g., spare parts) and disposed (e.g., waste), the environmental impact of these systems needs to be concerned. For this reason, an ecologic or sustainability perspective on the lifecycle should be taken into account.

To sum it up, a lifecycle model concerning CPS platforms in value networks should include technical, market and environmental perspectives for hardware, software and services both at type and instance level, as well as a perspective on the dynamic aspects of enterprise networks employing the platforms and CPS.

\section{Review of Lifecycle Models}

In this section, different lifecycle models are introduced covering a range of aspects that can be relevant for the management of CPS platforms in value networks. Domains utilizing the lifecycle concept defined their own characteristic lifecycle models to describe objects of interest in light of domain-specific problems. For this reason, there can be numerous models in each domain. Furthermore, among the domains very different models evolved. The differences typically concern the covered activities and situations of the model, as well as different emphasis on flows of information, material and energy. One of the application fields for lifecycle models is the domain of product lifecycle management (PLM). This domain is particularly rich in diverse perspectives on lifecycles. Table 1 provides a non-comprehensive selection of different lifecycle models. These models are selected because they provide a large spectrum of different aspects of lifecycles that should be taken into account when managing CPS platforms in value networks. Model A argues the lifecycle from a perspective of environmental impacts. A focus of this model is on three different scenarios that can be selected to discard the product, i.e., reuse, remanufacturing and recycling [13]. Model B is introduced to argue the suitability of item-level based product information handling to support PLM strategies [14]. Model C extends earlier work of Kiritsis and focuses on the information and knowledge flows among different lifecycle activities [15]. Model D is different from the other models in so far as it proposes three types of activity classes, i.e. engineering, operation and support [16]. Because of the three activity classes labeled as "chains", there is a similarity of the concept with Porter's traditional value chain concept characterizing an organization's activities [17]. 
Table 1. Selected examples of different lifecycle models

\begin{tabular}{|c|c|c|}
\hline Id & Domain & $\begin{array}{l}\text { Activities (the } \rightarrow \text { symbol represents the sequential order of } \\
\text { different activities) }\end{array}$ \\
\hline A & $\begin{array}{l}\text { PLM } \\
\text { (Environmental } \\
\text { Impact) [13] }\end{array}$ & $\begin{array}{l}\text { Raw material extraction } \rightarrow \text { Primary industry } \rightarrow \text { Manufac- } \\
\text { turing } \rightarrow \text { Use } \rightarrow \text { Product discard (Reuse, Remanufacturing, } \\
\text { Recycling) } \rightarrow \text { Treatment and final disposal }\end{array}$ \\
\hline B & $\begin{array}{l}\text { PLM } \\
\text { (Information } \\
\text { Management) } \\
{[14]}\end{array}$ & $\begin{array}{l}\text { Beginning of Life: Product design } \rightarrow \text { Manufacturing (de- } \\
\text { sign) } \rightarrow \text { Logistics } \rightarrow \text { Distribution } \\
\text { Middle of Life: Use } \rightarrow \text { Maintenance/Service } \\
\text { End of Life: Re-use } \rightarrow \text { Recycling } \rightarrow \text { Remanufactured } \rightarrow \\
\text { Disposal }\end{array}$ \\
\hline $\mathrm{C}$ & $\begin{array}{l}\text { PLM } \\
\text { (Information } \\
\text { Management) } \\
{[15]}\end{array}$ & $\begin{array}{l}\text { Beginning of Life: Conceptualization } \rightarrow \text { Definition } \rightarrow \\
\text { Realization } \\
\text { Middle of Life: Use } \rightarrow \text { Service } \rightarrow \text { Maintenance } \\
\text { End of Life: Reuse of products with refurbishing } \rightarrow \text { Reuse } \\
\text { of components with disassembly and refurbishing } \rightarrow \text { Ma- } \\
\text { terial reclamation without disassembly } \rightarrow \text { Material recla- } \\
\text { mation with disassembly } \rightarrow \text { Disposal with incineration } \rightarrow \\
\text { Disposal without incineration }\end{array}$ \\
\hline $\mathrm{D}$ & \begin{tabular}{|l} 
PLM \\
(Maintenance) \\
{$[16]$}
\end{tabular} & $\begin{array}{l}\text { Engineering Chain: Product design } \rightarrow \text { Process planning } \\
\rightarrow \text { Factory planning } \\
\text { Operation Chain: Production planning } \rightarrow \text { Production } \\
\text { scheduling } \rightarrow \text { Production control } \\
\text { Support Activities Chain: Marketing } \rightarrow \text { Procurement } \rightarrow \\
\text { Sales } \rightarrow \text { Distribution } \rightarrow \text { After Sales } \rightarrow \text { Quality } \rightarrow \text { Main- } \\
\text { tenance }\end{array}$ \\
\hline $\mathrm{E}$ & $\begin{array}{l}\text { IT-Systems } \\
\text { Development } \\
{[18]}\end{array}$ & $\begin{array}{l}\text { Stakeholder requirements definition } \rightarrow \text { System require- } \\
\text { ments analysis } \rightarrow \text { System architectural design } \rightarrow \text { Imple- } \\
\text { mentation } \rightarrow \text { System integration } \rightarrow \text { System qualification } \\
\text { testing } \rightarrow \text { Software installation } \rightarrow \text { Software acceptance } \\
\text { support Software operation } \rightarrow \text { Software maintenance } \rightarrow \\
\text { Software disposal }\end{array}$ \\
\hline $\mathrm{F}$ & Marketing [19] & Market development $\rightarrow$ Growth $\rightarrow$ Maturity $\rightarrow$ Decline \\
\hline G & $\begin{array}{l}\text { Enterprise } \\
\text { Networks [20] }\end{array}$ & Preparation $\rightarrow$ Setting Up $\rightarrow$ Operation $\rightarrow$ Decomposition \\
\hline
\end{tabular}

Model $\mathrm{E}$ is taken from the ISO/IEC 12207 standard and is a complex framework to describe individual software lifecycles in detail [18]. The complete framework consists of more than 40 activities but only the technical processes are covered in this paper. Model F concerns a widely accepted marketing perspective, where four phases are introduced describing a certain characteristic of revenue development [19]. Model $\mathrm{G}$ addresses the dynamic assembly and decomposition of enterprise networks through the lifecycle concept [20]. 
In summary, each of the selected models covers a certain aspect relevant to the management of CPS platforms in value networks. The required perspectives argued in section 2 are covered by the models, though the models do not provide a comprehensive view and must be revised according to the actual value network's requirements. One of the key challenges concerns the identification of relations among the models (e.g., sustainability and information perspectives), due to their differences in content.

\section{Conclusion and Outlook}

The paper is meant to be a position paper providing an overview of relations between CPS platforms as shared resources in value networks from a lifecycle oriented perspective. It argues that the complexity of the system poses challenges to current management approaches. It is argued that a driver of the complexity is related to the heterogeneous and typically asynchronous lifecycles of the system elements. In order to provide grounds for efficient management approaches of CPS platforms in value networks, important lifecycle perspectives are described. The paper closes with a selection of examples for lifecycle models that cover the relevant lifecycle perspectives.

While the provided selection of lifecycle models is a first step to create efficient management approaches for CPS platforms, further validation is necessary and questions from different perspectives still have to be answered. These questions concern many research domains, such as system interoperability, drivers and barriers of information exchange, employee acceptance of large scale CPS infrastructures, ITsecurity in dynamic enterprise networks, flexibility and standardization decisions for CPS-Platforms, and disposal of large scale CPS infrastructures or parts of it. A specific point of interest for future work is the refinement of existing lifecycle models, to establish a diversified collection of relevant activities and situations. Further research should investigate the relations between the different lifecycle models. This could be done through the identification of activities and situations that significantly influence each other across the different models. The relations between activities and situations from different models can be used to tailor management processes for specific value networks. A complementary research topic concerns quantification of the network's complexity problem. Real CPS platforms and real use cases could serve as valuable sources to gain quantifiable arguments for revised management approaches of CPS platforms within value networks.

\section{References}

1. Broy, M.: Cyber-Physical Systems: Wissenschaftliche Herausforderungen bei der Entwicklung. In: Broy, M. (ed.) Cyber-Physical Systems: Innovation Durch SoftwareIntensive Eingebettete Systeme, pp. 17-31. Springer, Heidelberg (2010)

2. Kagermann, H., Wahlster, W., Helbig, J. (eds.): Umsetzungsempfehlungen für das Zukunftsprojekt Industrie 4.0: Abschlussbericht des Arbeitskreises Industrie 4.0. acatech National Academy of Science and Engineering, Munich (2013) 
3. Pöppelbuß, J., Teucke, M., Werthmann, D., Freitag, M.: Managing the Life Cycle of ITBased Inter-firm Resources in Production and Logistics Networks. In: Kotzab, H., Thoben, K.D., Pannek, J. (eds.) Proceedings of the Fourth International Conference, LDIC 2014. Springer, Heidelberg (in print, 2014)

4. Schönberger, J., Kopfer, H., Kotzab, H.: A micro- and macro-economic view on shared resources in logistics. In: Kotzab, H., Thoben, K.-D., Pannek, J. (eds.) Proceedings of the Fourth International Conference, LDIC 2014 (Lecture Notes in Logistics), Bremen, Germany, Springer, Heidelberg (in print 2014)

5. Diemer, J.: Sichere Industrie 4.0-Plattform auf Basis von Community-Clouds. In: Bauernhansl, T., ten Hompel, M., Vogel-Heuser, B. (eds.) Industrie 4.0 in Produktion, Automatisierung und Logistik: Anwendung, Technologien und Migration, Springer, Vieweg (2014)

6. EPCglobal Inc. EPC Information Services (EPCIS) Version 1.0.1 Specification, http: / /www.gs1.org/gsmp/kc/epcglobal/epcis / epcis_1_0_1-standard-20070921.pdf

7. Lepratti, R., Lamparter, S., Schröder, R.: Transparenz in globalen Lieferketten der Automobilindustrie: Ansätze zur Logistik- und Produktionsoptimierung. Publicis Publishing, Erlangen (in print 2014)

8. Future Internet Technologies for MANufacturing industries (FITMAN): http://www.fitman-fi.eu/, http://www.fitman-fi.eu/

9. The European Factories of the Future Research Association (EFFRA), http: //www.effra.eu/

10. Factories of the Future, http://ec.europa.eu/research/industrial_technologies / factories-of-the-future_en.html

11. The Industrial Internet Consortium: A Nonprofit Partnership Of Industry, Government And Academia, http: / /www. iiconsortium.org/about-us.htm

12. Hülsmann, M., Windt, K.: Changing Paradigms in Logistics - Understanding the Shift from Conventional Control to Autonomous Cooperation and Control. In: Hülsmann, M., Windt, K. (eds.) Understanding Autonomous Cooperation \& Control: The Impact of $\mathrm{Au}-$ tonomy on Management, Information, Communication, and Material Flow, pp. 1-16. Springer, Heidelberg (2007)

13. Pigosso, D.C., Zanette, E.T., Filho, A.G., Ometto, A.R., Rozenfeld, H.: Ecodesign methods focused on remanufacturing. J. Clean. Prod. 18(1), 21-31 (2010)

14. Ranasinghe, D.C., Harrison, M., Främling, K., McFarlane, D.: Enabling through life product-instance management: Solutions and challenges. J. Netw. Comput. Appl. 34(3), 1015$1031(2011)$

15. Kiritsis, D.: Closed-loop PLM for intelligent products in the era of the Internet of things. Comput. Aided Des. 43(5), 479-501 (2011)

16. Kovacs, G., Kopacsi, S., Haidegger, G., Michelini, R.: Ambient intelligence in product lifecycle management. Eng. Appl. Artif. Intell. 19(8), 953-965 (2006)

17. Porter, M.E.: Competitive Advantage: Creating and Sustaining Superior Performance. Simon and Schuster, New York (2008)

18. ISO/IEC/IEEE: Standard for Systems and Software Engineering: Software Life Cycle Processes, IEEE STD 12207-2008, pp. 1-138. Geneva, New Jersey (2008)

19. Levitt, T.: Exploit the Product Life Cycle, http://hbr.org/1965/11/exploitthe-product-lifecycle/ar/1

20. Thoben, K.-D., Jagdev, H.S.: Typological issues in enterprise networks. Prod. Plan. Control 12(5), 421-436 (2001) 